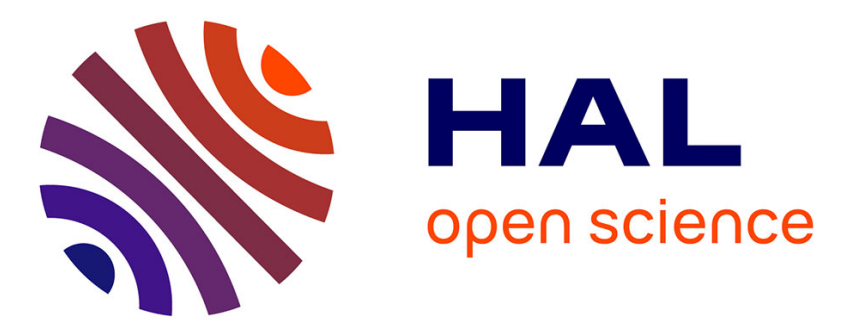

\title{
Priority Modes of Transport for Soybeans from the Center-West Region in Brazil
}

\author{
Cristina De Oliveira, Danilo De Castro, Nélio Dos Reis, João Dos Reis, Jair \\ Minoro Abe
}

\section{- To cite this version:}

Cristina De Oliveira, Danilo De Castro, Nélio Dos Reis, João Dos Reis, Jair Minoro Abe. Priority Modes of Transport for Soybeans from the Center-West Region in Brazil. IFIP International Conference on Advances in Production Management Systems (APMS), Sep 2015, Tokyo, Japan. pp.324-331, 10.1007/978-3-319-22756-6_40 . hal-01417501

\section{HAL Id: hal-01417501 \\ https://hal.science/hal-01417501}

Submitted on 15 Dec 2016

HAL is a multi-disciplinary open access archive for the deposit and dissemination of scientific research documents, whether they are published or not. The documents may come from teaching and research institutions in France or abroad, or from public or private research centers.
L'archive ouverte pluridisciplinaire HAL, est destinée au dépôt et à la diffusion de documents scientifiques de niveau recherche, publiés ou non, émanant des établissements d'enseignement et de recherche français ou étrangers, des laboratoires publics ou privés. 


\title{
Priority modes of transport for soybeans from the Center-West Region in Brazil
}

\author{
Cristina Corrêa de Oliveira ${ }^{1}$, Danilo Medeiros de Castro $^{2}$, Nélio Fernando dos Reis ${ }^{1}$, \\ João Gilberto Mendes dos Reis ${ }^{1}$, Jair Minoro Abe ${ }^{1}$ \\ ${ }^{1}$ Graduate Program in Production Engineering at Paulista University \\ Rua Dr. Bacelar 1212 CEP 04026-002 - São Paulo - SP - Brazil \\ \{crisolivedig.com.br, neliojundiaidig.com.br, \\ betomendesreis@msn.com, jairabe@uol.com.br\} \\ ${ }^{2}$ Grande Dourados Federal University \\ Rodovia Dourados / Itahum, Km 12 - Unidade II - Cep: 79.804-970 \\ \{danilomdecastro@gmail.com\}
}

\begin{abstract}
Choosing modes of transport for agricultural production involves uncertainties and decisions that affect logistics costs in the transportation of grains. This article intends to explain the use of the Paraconsistent Decision Method based on the Evidential Annotated Paraconsistent Logic E $\tau$ in the decision-making process involving experts in priority modes of transport in Agribusiness logistics. It deals specifically with the distribution and export of soybeans, the main Brazilian commodity, to the major Brazilian ports, considering the aspects and features of each mode of transport. Exploratory research was used and data were collected from questionnaires about the modes of transport. Results indicate that experts have chosen modes of transport with numeric outputs, where free costs and payable costs were considered, thereby pointing out the features that should be taken into account in each mode.
\end{abstract}

Keywords: Grains, Paraconsistency, Decision-making, soybean.

\section{$1 \quad$ Introduction}

Brazil was ranked as the world's eighth largest economy, with a Gross Domestic Product (GDP) of U\$ 2.4 trillion dollars in 2013 [3]. Agribusiness productivity has been increasing due to the high technology employed, and accounts for $22 \%$ of the Brazilian GDP [5].

The Center-West Region is the major producing area of soybean complex, with 41,785 thousand tons [5], and accounts for $48 \%$ of the domestic production. Soybeans are the most important commodity for the Brazilian trade balance. Despite their expressive share in exports, soybeans are a low aggregate-value product and require a well-performed logistics process that can reduce costs from raw material through adfa, p. 1, 2011.

(C) Springer-Verlag Berlin Heidelberg 2011 
exports. In order to meet the demand, the organizations must evaluate new transportation ways, whether combining or not modes of transport [10].

The overall purpose of this work is to employ the Paraconsistent Decision Method (PDM) that allows choosing the mode of transport for soybean distribution from the Center-West Region, considering some factors such as capacity, availability, reliability, periodicity and speed. The specific objectives of this study are deciding upon a tool that might help the decision-making process involving experts from several logistics areas and considering the stakeholders' opinions, and presenting a tool that allows a quantitative evaluation of all items, which results in numerical outputs generated by the model and can be easily understood and compared.

The PDM was developed on the basis of the Evidential Paraconsistent Annotated Logic $\mathrm{E} \tau$ (Logic $\mathrm{E} \tau)$, and its main advantage lies in the fact that input parameters are set according to the experts' thinking structure, thus consolidating a collective logic translated into mathematical expressions.

\section{$2 \quad$ Background}

\subsection{Paraconsistent, Paracomplete and Non-alethic Logics}

In what follows, we sketch the non-classical logics discussed in the paper, establishing some conventions and definitions. Let $T$ be a theory whose underlying logic is $L$. $T$ is called inconsistent when it contains theorems of the form $A$ and $\neg A$ (the negation of $A$ ). If $T$ is not inconsistent, it is called consistent. $T$ is said to be trivial if all formulas of the language of $T$ are also theorems of $T$. Otherwise, $T$ is called non-trivial.

When $L$ is classical logic (or one of several others, such as intuitionistic logic), $T$ is inconsistent if $T$ is trivial. So, in trivial theories the extensions of the concepts of formula and theorem coincide. A paraconsistent logic is a logic that can be used as the basis for inconsistent but non-trivial theories. A theory is called paraconsistent if its underlying logic is a paraconsistent logic.

Many logicians have appreciated issues such as those described above. In 1910, the Russian logician Nikolaj A. Vasil'év (1880-1940) and the Polish logician Jan Lukasiewicz (1878-1956) independently glimpsed the possibility of developing such logics. Nevertheless, Stanislaw Jaskowski (1996-1965) was in 1948 effectively the first logician to develop a paraconsistent system, at the propositional level. His system is known as 'discussive' (or discursive) propositional calculus. Independently, some years later, the Brazilian logician Newton C.A. da Costa (1929-) constructed for the first time hierarchies of paraconsistent propositional calculi $C_{\mathrm{i}}, 1 \leq i \leq \omega$ of paraconsis- 
tent first-order predicate calculi (with and without equality), of paraconsistent description calculi, and paraconsistent higher-order logics (systems $N F_{\mathrm{i}}, 1 \leq i \leq \omega$ ). Another important class of non-classical logics are the paracomplete logics. A logical system is called paracomplete if it can function as the underlying logic of theories in which there are formulas such that these formulas and their negations are simultaneously false. Intuitionistic logic and several systems of many-valued logics are paracomplete in this sense (and the dual of intuitionistic logic, Brouwerian logic, is therefore paraconsistent).

Consequently, paraconsistent theories do not satisfy the principle of noncontradiction, which can be stated as follows: of two contradictory propositions, i.e. one of which is the negation of the other, one must be false. In addition, paracomplete theories do not satisfy the principle of the excluded middle, formulated in the following form: of two contradictory propositions, one must be true [1], [2]. Finally, logics that are simultaneously paraconsistent and paracomplete are called non-alethic logics.

\subsection{Soybean Production}

Soybeans, corn and dry beans are the main agricultural products in Brazil. Soybean complex accounts for $49 \%$ of the grain cultivation areas [4]. Soybeans are greatly important because of their use in animal feed and human food industries; and they are the main product exported by the Country [3] [6].

The grain production in Brazil is estimated at 194 million tons spread over 56.9 million hectares, i.e. three million tons per hectare. Grain crops achieved the highest productivity rate in recent years, and production is expected to reach 199 million tons in 2015, and 252 million tons in the 2023/2024 season, with a productive area increasing to 67 million hectares [5].The Center-West region has favorable topography and climate conditions, attractive prices, and large areas available for cultivation; and in 2014, it accounted for $48.5 \%$ of the Brazilian production, despite its infrastructure deficiencies.

The transportation of grains can be made through several modes of transport, which are chosen according to the features, extension and benefits of the transport network, including costs of each mode of transport. Brazil's huge geographic area of 8.5 million $\mathrm{km}^{2}$ must be taken into account, with its 1.5 million kilometers of roads, 28 thousand kilometers of railroads, and 50,000 kilometers of navigable waterways, and four sea ports in the South and Southeast Regions that are used to export soybean grains, which totaled 36.3 million tons in 2014 [11].

Soybeans are the most important commodity in Brazil and account for $14 \%$ of the Brazilian trade balance [7]. The commodity, however, has a low aggregate-value and 
the choice for modes of transport may affect exports, considering that Center-West producers are between 1,000 and 2,500 kilometers away from the main Brazilian ports - the Port of Santos, located in the State of São Paulo, and the Port of Paranaguá located in the State of Paraná.

\subsection{Modes of Transport in Brazil}

The modes of grain transportation used in Brazil are waterways, railroads and roads $[11,12]$, and are distributed according to their ascending order of importance, respectively. Every mode of transport has operating characteristics, particularities, advantages and disadvantages.

The main characteristics of rail transport are the capacity to convey bulk freights with high-energy efficiency, low cost per ton in medium to long-distance conveyances, higher safety and lower risks of accident, robbery or theft when compared to other modes of transport [12]. Low speed and lack of flexibility concerning delivery changes are the main disadvantages of rail transport.

Water transport is advantageous for bulk cargo transportation over the open sea or through the coastline or rivers, and although freight volumes are advantageous, the good performance of this mode of transport depends on climate conditions [10].

Finally, the road transport is flexible for short-distance travels, but costs are highly dependent on fuel prices [13].

In Brazil, logistics costs account for $22 \%$ of the costs of export products. Those costs directly affect the GDP, with their $20 \%$ share, and transportation alone accounts for $56 \%$ of food costs [13]. The study of the modes of transport and the use of tools to elect them demonstrate the high importance of efficient transportation systems for the Brazilian economic development [11] [13].

\section{$3 \quad$ Materials and Methods}

This article aims to carry out an applied science research for exploratory purposes, which, according to Zikmund [8], should be carried out to solve doubtful situations or find out business opportunities, and is the first step to any subsequent research. It has a quantitative approach and uses questionnaires about the features and modes of transport. The attributes were defined as literature review. Thus, the characteristics associated to any item of transportation that one should take into account when deciding upon the modes of transport and their financial-economic aspects [9] are listed in Table 1: 
Table 1. Features of the Modes of Transport

\begin{tabular}{|l|l|}
\hline Aspects & Features \\
\hline \multirow{2}{*}{ Capacity } & Size of Vehicles \\
\cline { 2 - 2 } & Cargo Volume \\
\hline \multirow{2}{*}{ Availability } & Demand \\
\cline { 2 - 2 } & Services Available \\
\hline \multirow{2}{*}{ Reliability } & Delivery Changes \\
\cline { 2 - 2 } & Order Fulfillment \\
\hline \multirow{2}{*}{ Periodicity } & Period of Time \\
\cline { 2 - 2 } & Number of Travels \\
\hline \multirow{2}{*}{ Speed } & Handling Time \\
\cline { 2 - 2 } & Distance \\
\hline \multirow{2}{*}{ Costs } & Variable Cost \\
\cline { 2 - 2 } & Fixed Cost \\
\hline
\end{tabular}

The development of tools that may help choosing the modes of transport is essential to the organizational strategy, and the evaluation of the performance of transportation services may be used for such purpose [10].

For field research were asked only road modes, rail and waterway, which are systems available for the state of Mato Grosso do Sul, to eight logistics experts engaged in the academic area, in graduate and post-graduate programs, with 4 to 27 years of experience, one of them with fifteen years of experience in productive processes and logistics operations in trade business. The opinions, interests and skills of each of them were taken into account.

We used the Saaty scale [14] ranging from 1 to 9, where one means low importance of a feature and nine means extreme importance of a feature for the mode of transport, with intermediate levels of importance between 1 and 9. Data were normalized by using the same proportion and converting values in the 0 to 1 interval of the PDM, called favorable evidence. The complement rule was employed for contrary evidence.

\subsection{Data Analysis}

This research consisted of a group decision-making, where two groups were formed according to the time of experience of their members; the first group was formed by experts with up to ten years of experience and the second group was formed by experts with more than ten years of experience in logistics systems. Each expert opinion issued by type of modal, with the degree of favorable evidence for each attribute in Table 1; the degree of contrary evidence was calculated by the complement of favorable evidence, according to Table 2, which shows an excerpt from the original study.

Table 2. Database of specialist's evidences 


\begin{tabular}{|c|c|c|c|c|c|c|c|c|c|}
\hline \multirow[b]{3}{*}{ Aspects } & \multirow[b]{3}{*}{ Features } & \multicolumn{4}{|c|}{ Group > 10 } & \multicolumn{4}{|c|}{ Group $<=10$} \\
\hline & & \multicolumn{2}{|c|}{ spec 1} & \multicolumn{2}{|c|}{ spec 2} & \multicolumn{2}{|c|}{ spec 7} & \multicolumn{2}{|c|}{ spec 8} \\
\hline & & $\mu_{1}$ & $\lambda_{1}$ & $\mu_{2}$ & $\lambda_{2}$ & $\mu_{7}$ & $\lambda_{7}$ & $\mu_{8}$ & $\lambda_{8}$ \\
\hline \multirow{12}{*}{ Rail } & Size of Vehicles & 0,88 & 0,12 & 0,20 & 0,80 & 0,76 & 0,24 & 1,00 & 0,00 \\
\hline & Cargo Volume & 0,20 & 0,80 & 1,00 & 0,00 & 0,88 & 0,12 & 0,64 & 0,36 \\
\hline & Demand & 0,76 & 0,24 & 0,75 & 0,25 & 0,25 & 0,75 & 0,90 & 0,10 \\
\hline & Services Available & 0,52 & 0,48 & 0,75 & 0,25 & 0,20 & 0,80 & 0,88 & 0,12 \\
\hline & Delivery Changes & 0,52 & 0,48 & 0,64 & 0,36 & 0,25 & 0,75 & 1,00 & 0,00 \\
\hline & Order Fulfillment & 0,52 & 0,48 & 0,54 & 0,46 & 0,40 & 0,60 & 0,75 & 0,25 \\
\hline & Period of Time & 0,65 & 0,35 & 0,75 & 0,25 & 0,80 & 0,20 & 0,75 & 0,25 \\
\hline & Number of Travels & 0,64 & 0,36 & 0,75 & 0,25 & 0,75 & 0,25 & 0,75 & 0,25 \\
\hline & Handling Time & 0,75 & 0,25 & 0,75 & 0,25 & 1,00 & 0,00 & 0,75 & 0,25 \\
\hline & Distance & 0,64 & 0,36 & 0,88 & 0,12 & 0,75 & 0,25 & 0,77 & 0,23 \\
\hline & Variable Cost & 0,75 & 0,25 & 0,64 & 0,36 & 0,20 & 0,80 & 0,76 & 0,24 \\
\hline & Fixed Cost & 0,20 & 0,80 & 0,20 & 0,80 & 0,88 & 0,12 & 0,75 & 0,25 \\
\hline
\end{tabular}

The PDM was developed by using the Para-Analyzer based on Logic E $\tau$, with MIN and MAX operators, where MAX maximizes favorable evidences and minimizes contrary evidences in the group, and the MIN operator minimizes favorable evidences and maximizes contrary evidences between the groups. The use of both operators allows one to determine database inconsistencies [2]. The level of demand depends on the security and confidence in decision-making and the responsibility it entails [2]. The level of demand was set at 0.5 and the global analysis, whose result is equal to the factors' influence, is determined by the weighted average of the factors or features. The global analysis was calculated in duplicate considering only the aspects involved in the mode of transport, without taking into account the costs, indicated by the pink marker, and the global analysis with the costs, indicated in the $\mathrm{x}$ form by the green marker. By splitting the global analysis, we aimed to ascertain the influence of costs in the evaluation of the mode of transport.

\section{$4 \quad$ Outcomes of Logic E $\tau$}

The results indicate that the global analysis for water transport is in the central area of the Unit Square in the Cartesian Plane (USCP), which indicates a consensus in the analysis of some features, i.e. demand, delivery changes, order fulfillment, period of time and handling time, because of their low favorable evidence levels for grain transportation, as shown in Figure 1. 


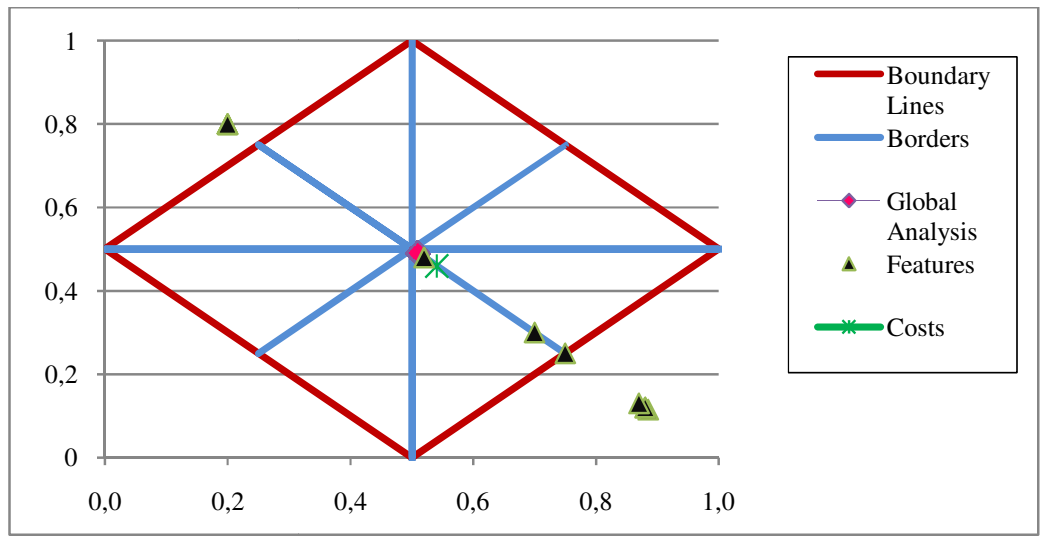

Fig 1. Water Transportation

The global analysis for rail transport is in the truth area, which evidences that it is the most appropriate type for transportation of grains, with all evidences falling in the same area, as shown in Figure 2.

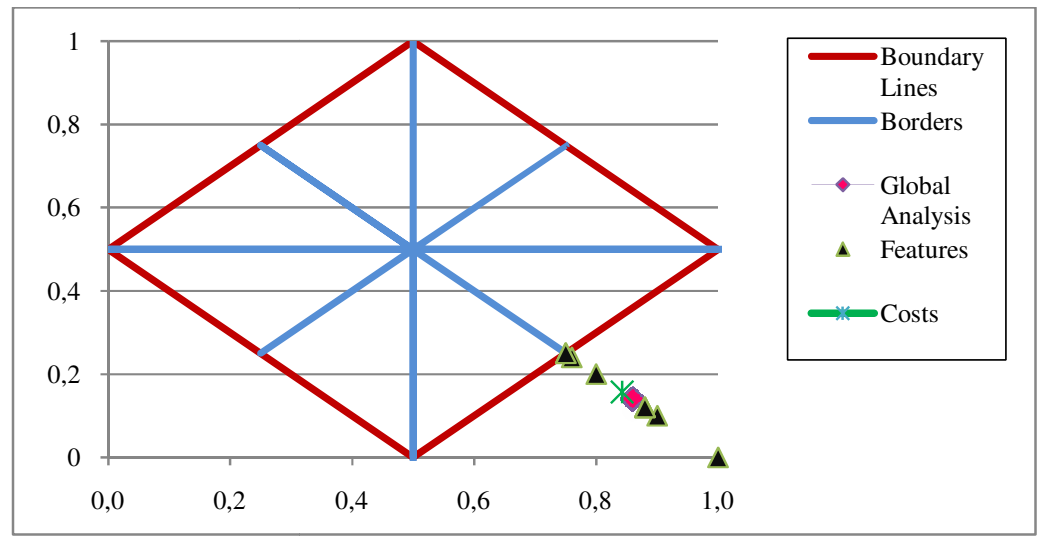

Fig. 2. Rail Transportation

The global analysis for road transport, see Figure 3, is in the truth area, with only two divergent points in the assessment, which is the capacity aspect with its features cargo volume and size. 


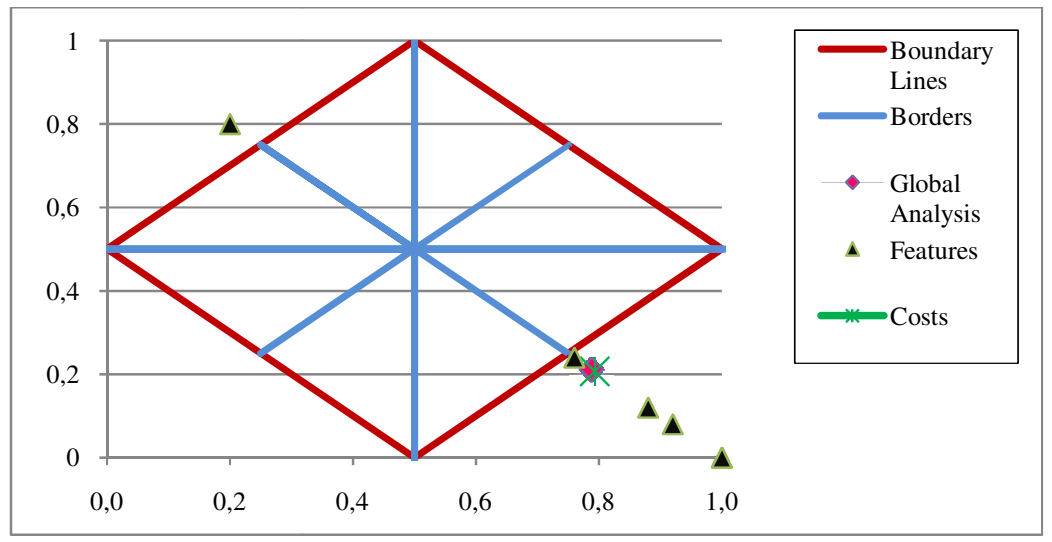

Fig. 3. Road Transportation

\section{$5 \quad$ Conclusion}

The research achieved its purpose of presenting a tool that allows a group decisionmaking, thereby quantifying the experts' opinions, which may be contradictory, and detailing the items of each assessment. One may ascertain that costs did not change significantly in the evaluation and helped decision makers choose the mode of transport.

This analysis also supports the modes of grain transportation used in Brazil, given that its waterway network spreads over $50,000 \mathrm{~km}$, which corresponds to $3.3 \%$ of the road network, and its efficient use depends on climate conditions. Despite its reduced extension, with 28 thousand kilometers, the railroad network shows the best favorable evidences for grain transportation when all features are taken into account. With a 1.5 million kilometer network, road is the most popular method of transportation in the Country, and any evaluation should take some of its features, especially cargo volume and size, into account, especially because of the high costs for low aggregate-value commodities.

\section{REFERENCES}

1. Abe, J.M., Paraconsistent Artificial Neural Networks: an Introduction, Lecture Notes In Computer Science 3214, Springer, 942-948 (2004)

2. Da Silva Filho, J.I., Torres, G.L., Abe, J.M.: Uncertainty Treatment Using Paraconsistent Logic - Introducing Paraconsistent Artificial Neural (2010)

3. Central Intelligence Agency: The world fact book, https://www.cia.gov/library/publications/the-world-factbook/geos/br.html 
4. Brasil. Ministério da Agricultura Pecuária e Abastecimento, Secretaria de Política Agrícola: . Cultura de Soja. Brasília (2015).

5. Brasil, Ministério da Agricultura, Pecuária e Abastecimento: Projeções do Agronegócio: Brasil 2013/2014 a 2023/2024 projeções de longo prazo (2014).

6. Brasil, Ministério Desenvolvimento, Indústria e Comércio Exterior, Secretaria de Comércio Exterior: Aliceweb, http://aliceweb.mdic.gov.br/

7. Brasil, Ministério do Desenvolvimento, Indústria e Comércio Exterior: Balança Comercial Brasileira Dados Consolidados (2015)

8. Zikmund, W.G., Babin, B.J., Carr, J.C., Griffin, M.: Business Research Methods, 8th edn. South-Western College Pub (2009)

9. Junior, I.C.L., de Almeida D'Agosto, M.: Modal choice for transportation of hazardous materials: the case of land modes of transport of bio-ethanol in Brazil Journal of Cleaner Production 19, 229-240 (2011)

10. Ballou, R.H.: Gerenciamento da Cadeia de Suprimentos. Bookman, Porto Alegre (2001)

11. Brasil, Ministério dos Transportes: Projeto de Reavaliação de Estimativas e Metas do PNLT (2012)

12. Brasil, Agência Nacional de Transportes Terrestres http://www.antt.gov.br/index.php/content/view/4971/Caracteristicas.html

13. The World Bank: How to decrease freight logistics costs in Brazil. Washington, DC (2012)

14. Saaty, T.L.: How to make a decision: The Analytic Hierarchy Process. European Journal of Operational Research, Vol. 48 No. 1, 9-26 (1990) 